\title{
Easier said than done
}

\author{
Edward D. Verrier, MD
}

From the University of Washington, Seattle, Wash.

Disclosures: Author has nothing to disclose with regard to commercial support.

Received for publication Aug 9, 2018; accepted for publication Aug 10, 2018; available ahead of print Sept 18, 2018 .

Address for reprints: Edward D. Verrier, MD, University of Washington, 1959 Pacific NE St, Box 356310, Seattle, WA 98195 (E-mail: edver@u.washington.edu).

J Thorac Cardiovasc Surg 2019;157:678-9

0022-5223/\$36.00

Copyright (c) 2018 by The American Association for Thoracic Surgery

https://doi.org/10.1016/j.jtcvs.2018.08.014

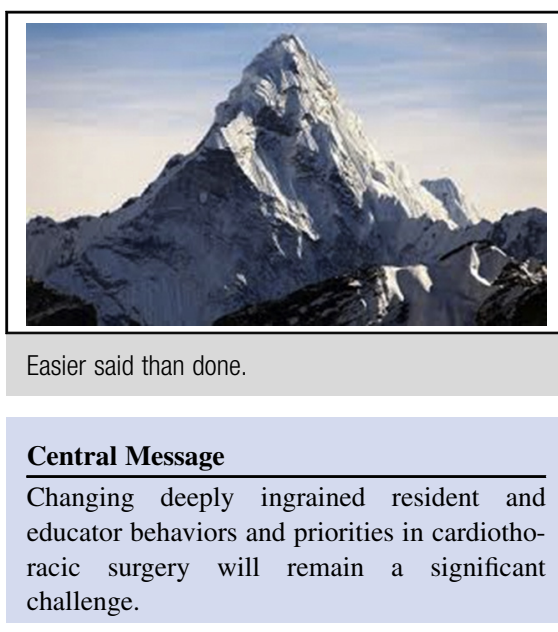

See Article page 671
Jason Han and William Patrick ${ }^{1}$ have written a limited overview of the current challenges in cardiothoracic education from the resident learner perspective. The main 2 conclusions of the article are that formal residency training in surgery must be augmented by practicing outside the operating room (simulation) and by encouraging coaching with formative feedback to achieve the higher level of "deliberate" practice. These trainees have extended many of the concepts introduced in the 2016 American College of Surgeon's Gibbons lecture, ${ }^{2}$ which emphasized grit, mindset, deliberate practice, and coaching as insights to improve our current educational culture in surgery. Certainly, I would concur with their message. Adult learning is most effective when it is experiential, repetitive, and learnercentric rather than top-down teacher-centric. However, significant challenges remain before meaningful adoption of these emerging concepts will occur.

First from the learner perspective, millennium learners are different, and our current world of surgery is also different in contrast to earlier generations. Millennials are technologically savvy, are process oriented and not goal oriented, are able to access information effortlessly, and demand immediate communication. ${ }^{3}$ Millennials struggle with lifestyle balance, desire mental and physical wellness, and value diverse relationships. The concept they are going to leave the hospital to practice or independently study is a significant challenge (which I note every day as the residency program director at the University of Washington). Millennials prefer information to be readily provided but might not necessarily understand the difference between information and long-term retrievable mental imagery or knowledge.

Second, from the educator perspective, there is a significant misalignment of incentives. Faculty now work for the hospital rather than the school of medicine. In 2018, most hospitals run on a fine line between solvency and debt. Faculty are valued for their financial contributions, and cardiothoracic surgery contributes more to the hospital bottom-line than most other medical specialties. Then, academic faculty must be promoted, so the result is that educational responsibilities are consistently relegated to a lower priority. In addition, expertise is not transferable across domain, so simply being a good surgeon is not enough to be a good educator. Yet, meaningful faculty development takes time, money, and commitment and is most often neglected.

Finally, from the cultural perspective, if it was good enough for me it must be good enough for this generation of learners, even though complexity is up, duty hour restrictions are in place, and faculty are distracted. Cultural change is difficult, particularly for surgeons, and usually takes generations rather than simply because "change" might make intellectual sense. As the book Switch: How to Change Things When Change Is Hard notes, change not only must make intellectual sense (direct the rider) but also must stimulate a visceral, emotional feeling of Yes! (motivate the elephant), and of course as leaders we must show how change can be accomplished (shape the path).

So then, what kind of path might we envision? All elite athletes, performing artists, and master surgeons require lifelong practice, constructive formative feedback, rehearsal, and ongoing coaching. The elite performer must overlearn so skill proficiency becomes second nature, cross-train to develop complementary skills, and devise safe simulations to allow performance without fear. ${ }^{5}$ This will require a significant change in culture and a better alignment of incentives for both learner and educator. We must change the conversation, which is a good definition of leadership. Much easier said than done. 


\section{References}

1. Han JJ, Patrick WL. See one-practice-do one-practice-teach one-practice: The importance of practicing outside of the operating room in surgical training. $J$ Thorac Cardiovasc Surg. 2019;157:671-7.

2. Verrier ED. The elite athlete, the master surgeon. J Am Coll Surg. 2017;224: 225-35.

3. Toohley SL, Wray A, Wiechmann W, Lin M, Boysen-Osborn M. Ten tips for engaging the millennial learner and moving a (emergency medicine) residency curriculum into the 21st century. West J Emerg Med. 2016;17:337-43.

4. Heath C, Heath D. Switch: How to Change Things When Change Is Hard. New York, NY: Broadway Books; 2010.

5. Ericsson A, Pool R. Peak: Secrets from the New Science of Expertise. New York, NY: Houghton Mifflin Harcourt; 2016. 